\title{
Friction welding of 304 austenitic stainless steel tube to tube plate joints using an external tool
}

\author{
Subbanchetty PANDIA RAJAN*, Selvaraj SENTHIL KUMARAN** \\ and Lakshmi annamalai KUMARASWAMIDHAS*** \\ *Department of Mechanical Engineering and Mining Machinery Engineering, \\ Indian Institute of Technology (ISM), Dhanbad, Jharkhand, India-826004. \\ "Department of Mechanical Engineering, RVS Educational Trust's Group of Institutions, \\ RVS School of Engineering \& Technology, Dindigul - 624005, Tamil Nadu, India. \\ E-mail: sskumaran@ymail.com \\ Department of Mechanical Engineering and Mining Machinery Engineering, \\ Indian Institute of Technology (ISM), Dhanbad, Jharkhand, India-826004.
}

\section{Received 14 May 2015}

\begin{abstract}
The present study has been focused on friction welding of AISI 304 austenitic stainless steel tube to tube plate joints using an external tool. Friction welding of tube to tube plate using an external tool (FWTPET) is invented in the year 2006. In the present study FWTPET joints, micro and macro structure, hardness profile have been studied. AISI 304 austenitic stainless steel tube and tube plates are welded by TIG welding process and metallurgical properties such as hardness, micro and macro structure has been compared with the joints of FWTPET process. FWTPET joints have been showed that better metallurgical aspects like fine grains at the interface, heat affected zone (HAZ) and a better hardness profile when compared to TIG welded joints.
\end{abstract}

Key words: FWTPET process, TIG welding, Tube to tube plate welding, Friction welding, External tool

\section{Introduction}

The major parts of a shell and tube heat exchanger are the shell, heads, tubes, tube plate and baffles. Experience gained by the manufacturer and users of heat exchangers in the power and chemical industries confirm that the joints between heat exchanger tube plate and tube walls is one of the key elements, which are decisive for longevity and reliability of such equipment. On one hand this importance is due to the great number of joints within exchanger and on the other hand the simultaneous effects from corrosion and thermal as well as mechanical stresses, which can cause the gradual degradation of the joint quality in operating conditions. It is well known that in many cases this degradation leads to unacceptable leakage in the whole heat exchanger. Due to the complexities of the design and fabrication of tube-to-tube plate joint, there are more potential leak paths at this location than with any of the other components.

AISI-304 stainless steel is widely used because of its better corrosion resistance and it's relatively low cost as compared to other 300 series steels. AISI-304 stainless steel is used in chemical, petrochemical and fertilizer industries and as equipment in dairy, food processing, pharmaceutical industries and in households such as kitchenware, cryogenic vessels and as heat exchanger components. When AISI 304SS is employed as the construction material the design and fabrication of the tube to tube plate joints using fusion welding becomes complicated due to the properties of AISI-304 stainless steel and the necessary controls needed to produce a quality weld that has good ductility, corrosion resistance and strength. Difficulties encountered during fusion welding of stainless steels include stress corrosion cracking, delta ferrite and sigma phase formation and heat affected zone (HAZ) is prone for sensitization by formation of intergranular $\mathrm{Cr}$-rich carbides, which deteriorates the corrosion properties of the welded joint.

However solid state welding can eliminate the above metallurgical problems. In particular friction welding can be 
used successfully to join a much broader spectrum of materials than fusion welding. Hence, there is a need to develop highly efficient joining methods for a specific application such as tube to tube plate joints, which can achieve higher strength and quality more consistently than with the fusion welding processes.

A study has been carried out to explore the explosive welding of tube to tube plate. From observation it is found that the parallel geometry set-up and high detonation-velocity explosive material is feasible but, the kinetic energy of the impacting tube and distortion of the tube-plate are very important factor for securing satisfactory weld (Krishanan and Kakodkar, 1990).

Friction welding of tube to tube plate using an external tool (FWTPET) is invented in the year 2006. FWTPET is a solid state joining process that produces coalescence between tube and tube plate by the heat generated due to friction between the work piece and the external tool.

FWTPET process is suitable to produce high quality leak proof joints. Further, it is also energy efficient, environment friendly, versatile, savings in materials and low production time, when compared to traditional welding techniques. Materials' being welded doesn't melt and recast and hence weld joints produced by FWTPET process exhibits enhancement in mechanical and metallurgical properties, better repeatability and capability to join dissimilar metals. Further the tube and plate are stationary and hence they can be weld of any dimension (Muthukumaran, 2010).

Some of the welding parameters that determine the quality of welds produced by FWTPET include tool rotational speed, shoulder diameter and clearance between pin and tube. Significant improvement in metallurgical and mechanical properties of FWTPET process depends on the efficient control of its process parameters. The optimized process parameters are reported and the tool rotation speed possesses highest contribution followed by the shoulder diameter and the pin clearance (Senthil Kumaran, et al., 2010). In one of the artificial neural network study (ANN) has been used to predict the strength behavior of FWTPET process. The optimal architecture has been used to predict the output process parameter, the predicted output and input parameters have been optimized using Genetic Algorithm (GA). GA optimized and experimentally determined process parameters are compared and the deviation is found to be minimal (Senthil Kumaran, et al., 2011). In another study influences of rotational speed on the microstructure and mechanical properties of 304SS friction welded joints is estimated and observed that the use of higher rotational speed and shorter friction time increases the tensile strength of friction-welded joints (Zdemir, 2005). In one of the available literatures the effects of process parameters on metallurgical and mechanical properties of 304SS friction-welded joints and the correlation between the microstructure and the joint strength has been discussed (Sathiya, et al., 2005). It is suggested that the rapid formation of the sigma phase is related to the transformation of austenite to delta-ferrite in the stir zone, from introduction of high strain and dynamic recrystallization during FSW of 304SS (Park, et al., 2003). FSW of 304SS led to a relatively low degree of sensitization in the HAZ than TIG welding, which could be explained as being due to the short duration at sensitization temperatures (Park, et al., 2004). An experimental study on effect of preheating on the residual stress in type 304 stainless steel weldment shown that the residual stress increases with the increase of preheat temperature. Preheating will induce a wider heat-affected zone and a poor strength of base metal than the conventional welding in type 304stainless steel (Lin and Lee, 1997).

FWTPET has been mainly studied with low melting temperature materials such as aluminum and its alloys (Muthukumaran, et al., 2010). FWTPET has been employed to achieve satisfactory joints with better mechanical properties and cost efficiency than conventional fusion welding techniques. Other advantages include formation of fine grains, low distortion and absence of segregation. The objective of the present study is to weld tube to tube plate joints of 304 stainless steel using tungsten tool by FWTPET process and to study the metallurgical properties of tube to tube plate joint.

\section{Experimentation:}

\subsection{FWTPET Welding:}

The FWTPET machine developed in-house is shown in Fig. 1(a). The FWTPET configuration consists of a vertical tool holder, table (for holding tube to tube plate assembly in position) and supporting structure.

Tungsten and its alloys are refractory metals with a very high melting point and high density and hence in the present study tungsten alloy is used as external tool material. The tungsten tool is manufactured by powder metallurgy technique through hot pressing compaction. FWTPET tungsten tool consists of shoulder and a pin as shown in the Fig. 1(b) and tool dimensions are according to the optimum values obtained from available literature (Senthil Kumaran, et al., 2010).

FWTPET is a simple process where there are few steps to be followed 
1) Sample preparation:

Plate: In the present study $10 \mathrm{~mm}$ rolled plates of dimension (50 x $50 \mathrm{~mm}$ ) are prepared, a hole of $19 \mathrm{~mm}$ is drilled at the center and edges are made flat.

Tube: 19mm outer diameter with $6 \mathrm{~mm}$ thickness tube is prepared, faces are made flat and holes are drilled around the circumference of the faying surfaces of the tube.

2) Assembly:

Tubes are inserted into tube plate hole as shown in the Fig. 2 (a) using a mallet and this whole assembly is inserted in a backing block which acts as a support for the plate to avoid distortion during welding. The experimental and numerical investigation of FWTPET process revealed that the employment of backing block greatly enhances the quality of the joints produced (Senthil Kumaran, et al., 2010).

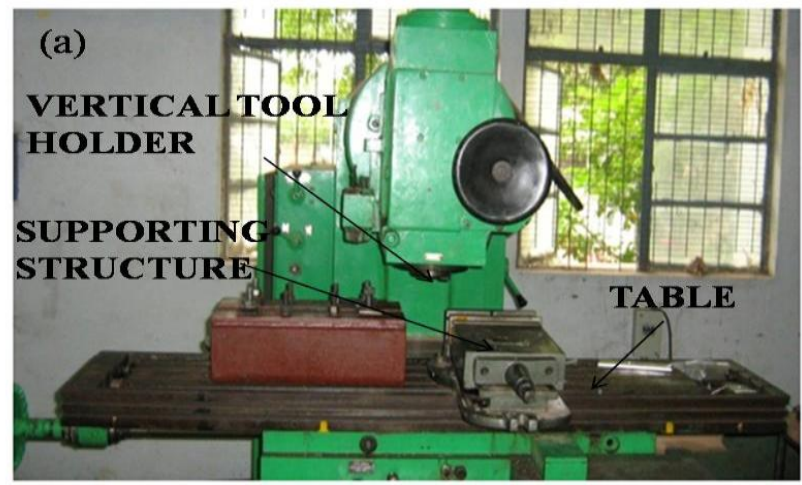

Fig.1 (a) FWTPET machine developed in-house

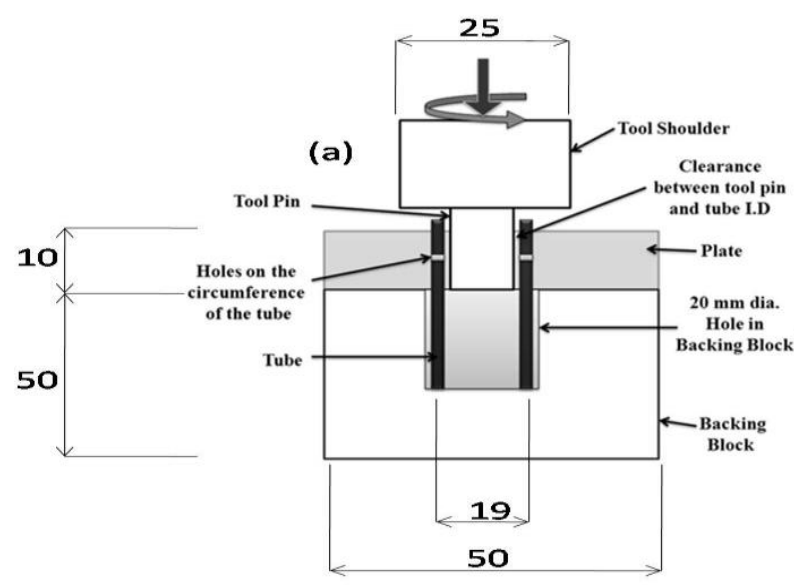

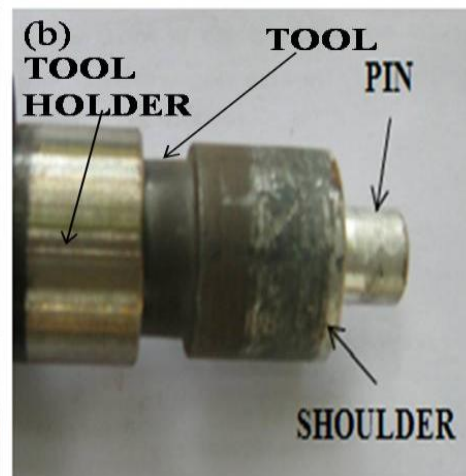

(b) Tungsten tool used for FWTPET process

Fig. 2 (a) whole welding setup fixed on FWTPET machine, (b) Principle behind bond formation in FWTPET process

\section{3) Alignment:}

Whole assembly with the backing block is placed under the tool and clamped tightly in vice in such a way that there should be clearance between the tool pin and the tube inner diameter, as shown in Fig. 2 (a).

4) Welding:

The basic requirements to achieve a FWTPET weld by temperature \& pressure which are high enough for forging. The tool is lowered during rotation and heat is created due to friction when the shoulder touches the plate as shown in Fig. 2(b). The metal reaches the plastic condition and flows metal towards the center of the tool axis (Muthukumaran, 2010).

The metal is flowed in-between the clearance of tube and tube plate and the tube material movement is restricted by the cylindrical pin which will act as an anvil as shown in the Fig. 2(b). Therefore enormous pressure and 
temperature has been generated between the tube and the plate interface. Hence a better metallurgical bond is achieved in-between tube and tube plate (Muthukumaran, 2010). In the present study, the chemical composition of plate and tube is shown in the Table 1.

FWTPET 304SS joints has been obtained at lower speeds such as $1100 \mathrm{rpm}, 1400 \mathrm{rpm}$ depicts defective weld because there is no sufficient heat is created on the top surface of the plate and higher tool rotational speeds (more than $1600 \mathrm{rpm}$ ) has been influenced defect free weld due to more heat generation with short time interval in between tube and plate of FWTPET process.

Table 1 Chemical composition of plate and tube material

\begin{tabular}{|c|c|c|c|c|c|c|c|c|c|}
\hline Elements & \% $\mathrm{C}$ & $\overline{~ \% ~ M n ~}$ & $\% \mathrm{Si}$ & $\% \mathrm{Cr}$ & $\% \mathrm{Ni}$ & $\% \mathrm{~S}$ & $\% \mathrm{P}$ & \% Мo & $\% \mathrm{Fe}$ \\
\hline $\begin{array}{c}\text { Plate } \\
\text { AISI 304SS } \\
\end{array}$ & 0.05 & 1.72 & 0.62 & 18.0 & 8.28 & 0.25 & 0.01 & 0.12 & Balance \\
\hline $\begin{array}{c}\text { Tube } \\
\text { AISI 304SS }\end{array}$ & 0.05 & 1.72 & 0.62 & 18.4 & 8.77 & 0.02 & 0.01 & 0.12 & Balance \\
\hline
\end{tabular}

\subsection{TIG welding of tube to tube plate:}

In the present study an attempt is made to compare the welds made by FWTPET process and TIG welded joints. Joint configurations have been considered for doing TIG welding as per ASTM SEC VIII is shown in Fig. 3. Filler wire recommended for doing welding of 304 SS is ER308L and the chemical composition is give in Table 2.

Table 2 Chemical composition of Filler wire ER308L used for TIG welding

\begin{tabular}{l|l|l|l|l|l|l|l|l|l}
\hline Elements & $\mathbf{C}$ & $\mathbf{M n}$ & $\mathbf{S i}$ & $\mathbf{C r}$ & $\mathbf{N i}$ & $\mathbf{S}$ & $\mathbf{P}$ & $\mathbf{N}$ & $\mathbf{F e}$ \\
\hline Wt. (\%) & 0.03 & 1.65 & 0.43 & 19.70 & 9.30 & 0.02 & 0.021 & 0.05 & Balance \\
\hline
\end{tabular}

In this present study filler wire of $1.6 \mathrm{~mm}$ diameter is used. This filler wire is having typical application in fabricating equipment's for dairy, chemical \&fertilizer industries, oil refineries, specially used for root run. TIG welding of 304SS tube to tube plate joints are welded with different heat inputs and weld quality has been assessed by doing peel test and joints which have not shown any crack in the weld are considered for comparison with FWTPET welded joints and the parameters considered is shown in the Table 3.
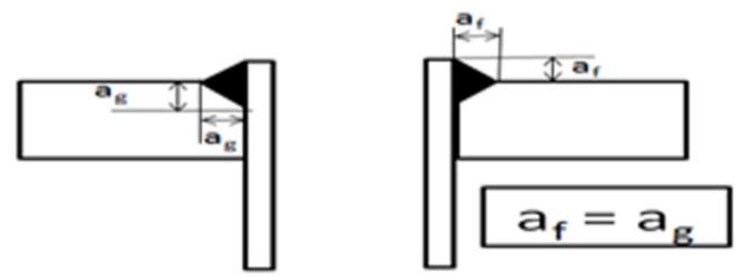

Fig. 3Acceptable tube to tube plate welds as per ASTM standards

Table 3 Process parameter considered for TIG welding

\begin{tabular}{c|c|c|c|c|c|c}
\hline \hline $\begin{array}{c}\text { Power } \\
\text { source }\end{array}$ & $\begin{array}{c}\text { Current } \\
(\mathbf{A})\end{array}$ & $\begin{array}{c}\text { Voltage } \\
(\mathbf{V})\end{array}$ & $\begin{array}{c}\text { Speed } \\
(\mathbf{m m} / \mathbf{S e c})\end{array}$ & $\begin{array}{c}\text { Gas flow rate (Ar) } \\
(\mathbf{L i t} / \mathbf{m i n})\end{array}$ & $\begin{array}{c}\text { Efficiency of the } \\
\text { process }(\boldsymbol{\%})\end{array}$ & $\begin{array}{c}\text { Heat Input } \\
(\mathbf{J} / \mathbf{m m})\end{array}$ \\
\hline DCEP & 45 & 15.8 & 0.88 & 8 & 0.6 & 484 \\
\hline
\end{tabular}

\subsection{Microstructure studies:}

Tube to tube plate joints are sectioned in the transverse direction and samples have been prepared with emery sheet of different grades; further polishing has been done using alumina polishing and diamond polishing with $1 \mu \mathrm{m}$ diamond paste. This is followed by etching for microstructure study, electrolytically etched with $10 \%$ Oxalic acid at $15 \mathrm{~V}$ for 45 Sec. Scanning electron microscope (SEM) image are taken at the joint interface at higher magnification and the variation in chemical composition across the interface is assessed with Energy Dispersive Analysis of X-rays (EDAX). 


\subsection{Hardness Measurements:}

Micro Vickers Hardness survey with diamond pyramid indenter having $136^{\circ}$ apex angle is used to study the hardness across the weldment covering weld interface, HAZ and base metal at $0.5 \mathrm{~kg}$ load. Indentations are at a span of $0.5 \mathrm{~mm}$ for the comparison of hardness of different zones.

\section{Results and Discussion:}

\subsection{FWTPET Joint microstructure and macrostructure analysis:}

The microstructures of the welded joint obtained with the process parameters (1800rpm, 1mm plunge depth, $1 \mathrm{~mm}$ tube projection) are analyzed at different weld zones, and typical micrographs at different zones in the joint are shown in Fig. 4. The position A is indicated that the weld centre line of in-between of tube and plate of FWTPET welding process and it is represented as joint interface or mid-line of the two material during joining of FWTPET process. The position B is represented as fine grain structure during friction welding process and severe plastic deformation taking place due to pressure and temperature. Compared to the base metal, the changes in microstructure are observed at the weld zone interface. The grains at base metal (plate and tube) are $89 \mu \mathrm{m}$ coarser and a fine grain structure has been observed at $16 \mu \mathrm{m}$ in the weld zone interface through linear intercept method as per ASTM standard as shown in Fig. 4 (point B). From the different zones microstructure along the interface we can see that the plate material is flowing in to the tube and making an interlocking effect (point A) and there is no sensitization observed in the tube side or plate side at the interface but the place where the tool shoulder touches the plate is sensitized (point E). It is clear from the microstructures at different zones there is a complete metallurgical bond throughout the thickness of the plate and is revealed by SEM images as shown in Fig. 5(a). From the EDAX analysis it is clear that there is no compositional variation across the interfaces as shown in the Fig. 5(b)

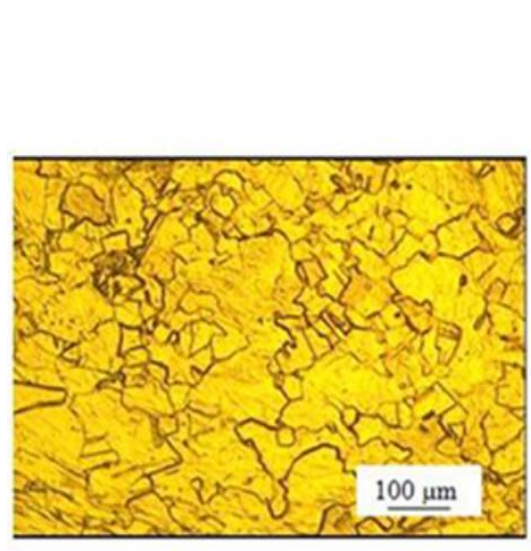

(C) HAZ Tube
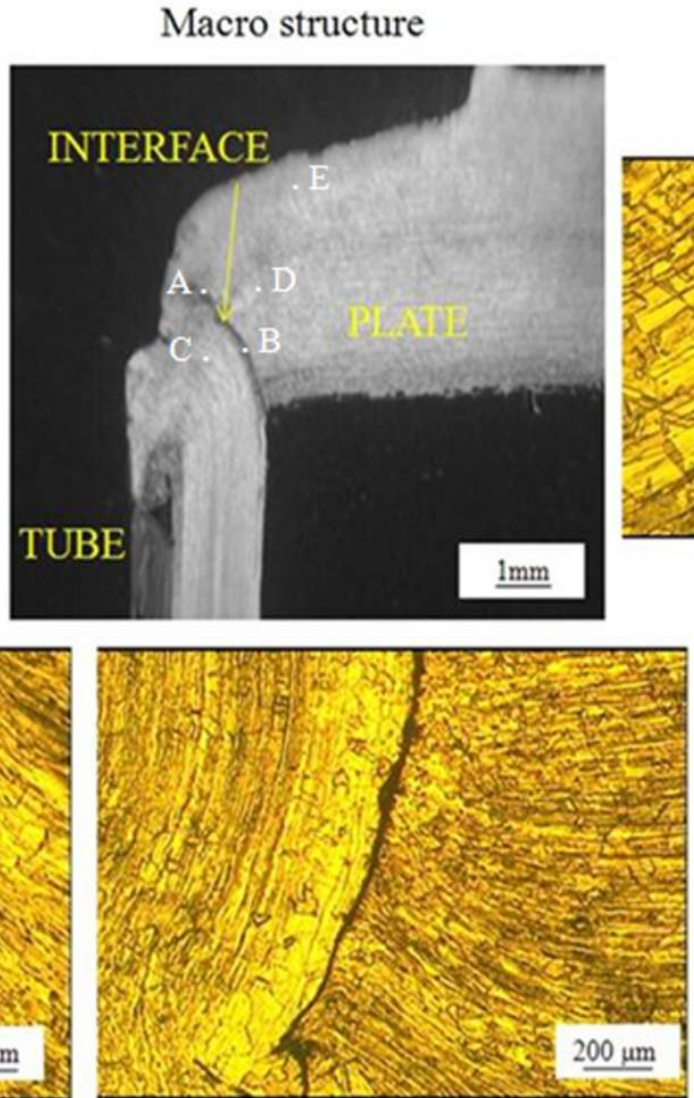

(B) Finer grains at the interface

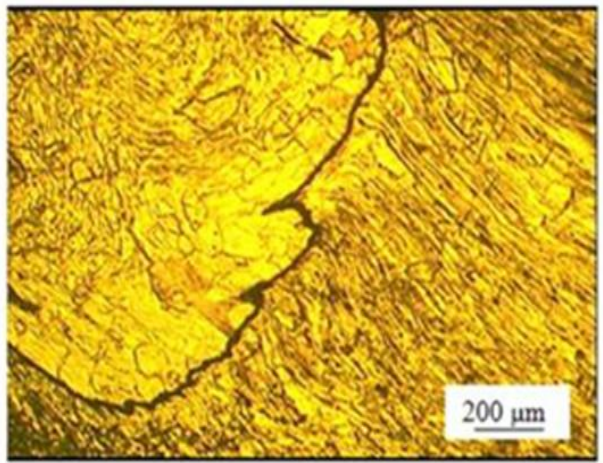
(A) Weld Interface between tube and plate

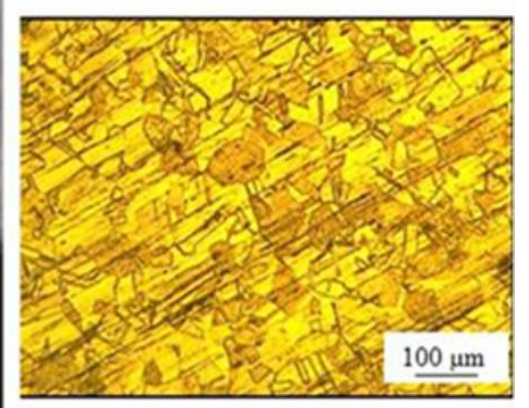

(D) HAZ Plate

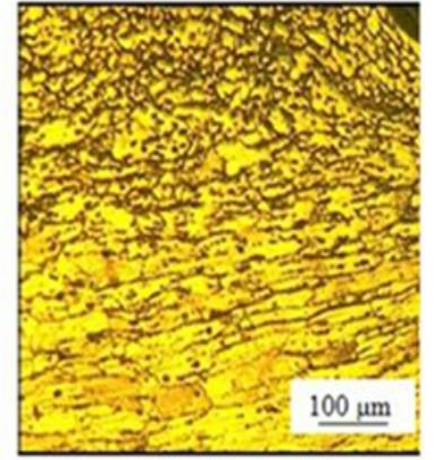

(E) Sensitization at top of plate where tool shoulder touches

Fig. 4 Microstructure of FWTPET processed joint at different zones 


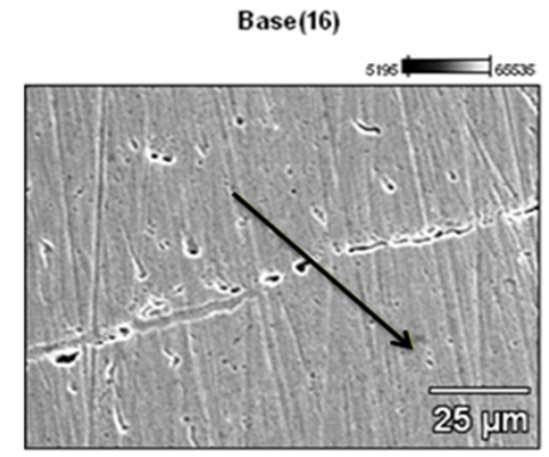

(a)

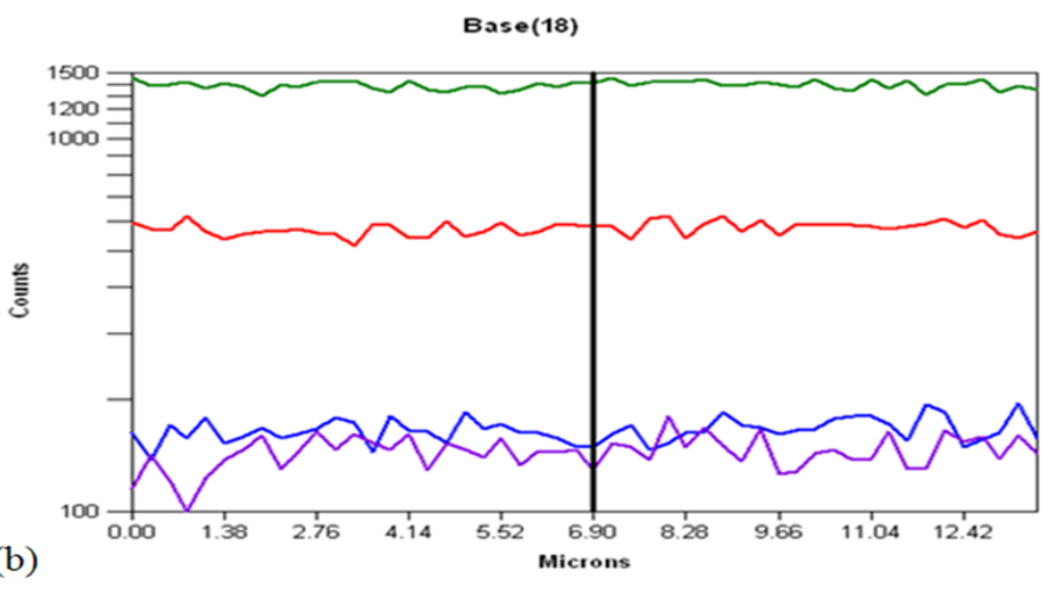

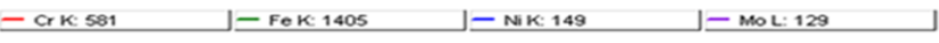

Fig. 5 Interface between tube and plate (a) SEM image (b) EDAX analysis

\subsection{TIG welded joint microstructure and macrostructure analysis}

TIG welding weld metal microstructures consist of $\delta$-Ferrite as the primary solidification phase. The dark dendrites is shown in Fig. 6(a). The core of the $\delta$-ferrite dendrites, which forms at the beginning of solidification and high density $\mathrm{Cr}$, while the outer portions, which form as temperature decreases, have lower chromium contents. Upon cooling into the $(\delta+\gamma)$ two-phase region, the outer portions of the dendrites having less $\mathrm{Cr}$ transform to austenite, thus leaving behind $\mathrm{Cr}$-rich skeleton of $\delta$-ferrite at the dendrite cores. This skeletal ferrite is called lathy or lacy ferrite [15-16], as shown in Fig. 6(a).

Because of compositional variation between the filler wire and base metal, four zones have been found in the weldment, the weld metal, unmixed zone, the fusion line and HAZ. The weld metal next to the fusion line, labeled as the unmixed zone, suggesting stagnant melted base metal unmixed with the filler metal (SindoKuo, 2003) as shown in the Fig. 6(b).
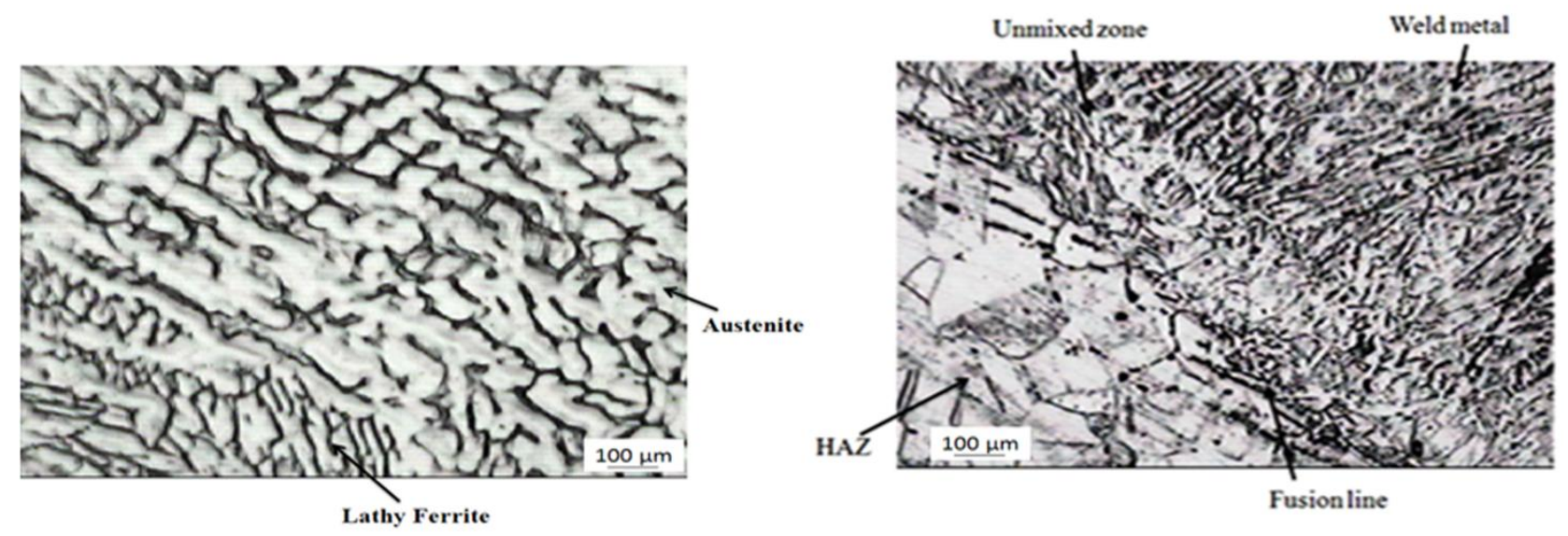

Fig. 6 Microstructure of TIG welded joint showing (a) Different phases (b) Different zones in the weldment.

The microstructures of the weld joint obtained with the process parameters (Heat input $484 \mathrm{~J} / \mathrm{mm}$ ) has been analyzed at different weld zones and typical micrographs at different zones in the joint is shown in Fig. 7 and it is observed that within the weld cellular structure is found at the fusion zone fallowed by columnar dendritic structure and as it goes towards the top surface equiaxed dendritic structure and the tube side HAZ is having coarse grains and sensitized which will deteriate the corrosion properties. Classification of sensitized microstructure according to ASTM A-262: says that it is of dual mode (John, et al.,2005). 


\subsection{Hardness Profile:}

From the hardness profile of FWTPET welded joints, it is observed that hardness value at the interface between tube and plate is comparable to base metal hardness as shown in the Fig. 8 and hardness near the interface is found to have more hardness because of recrystallization occurs in shorter duration so fine grains are formed near the interface as shown in the Fig. 4. So that, there is a rise in hardness near the interface and in the HAZ due to coarse grains formation there is drop in the hardness when compared to the base metal.
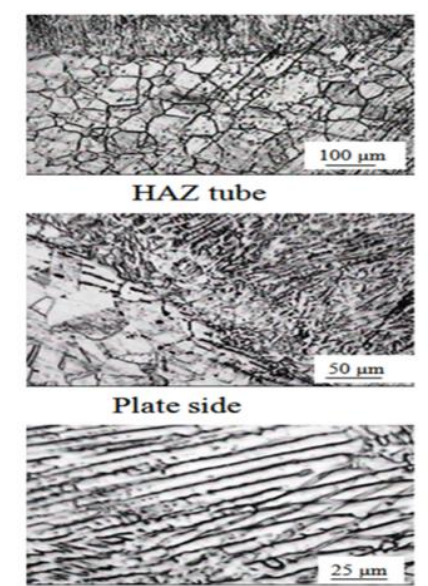

At fusion line cellular structure

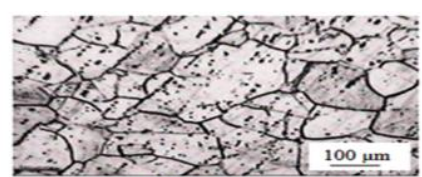

HAZ tube
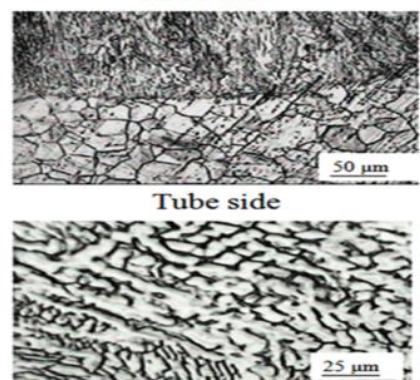

Middle dendritic structure

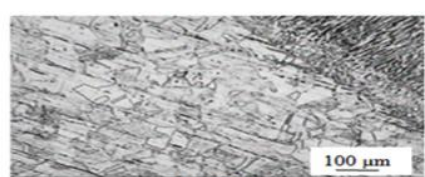

HAZ plate

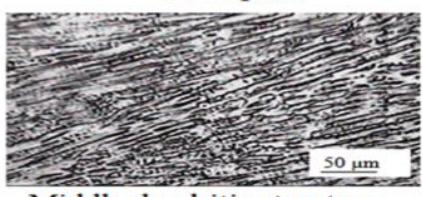

Middle dendritic structure

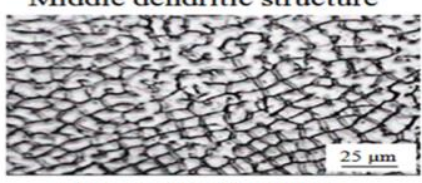

Top equi axis grains

Fig. 7 Microstructure of TIG weldment with $484 \mathrm{~J} / \mathrm{mm}$ heat input

Hardness profiles for TIG welded joints have been showed that at the weld center there is increase in hardness because of fine equi axed grains formation at the top and there is a drop in hardness at the HAZ due to coarse grains. From the hardness profile as shown in the Fig. 8, it is found that the width of HAZ is high in TIG welded joints when compared with joints welded by FWTPET process.

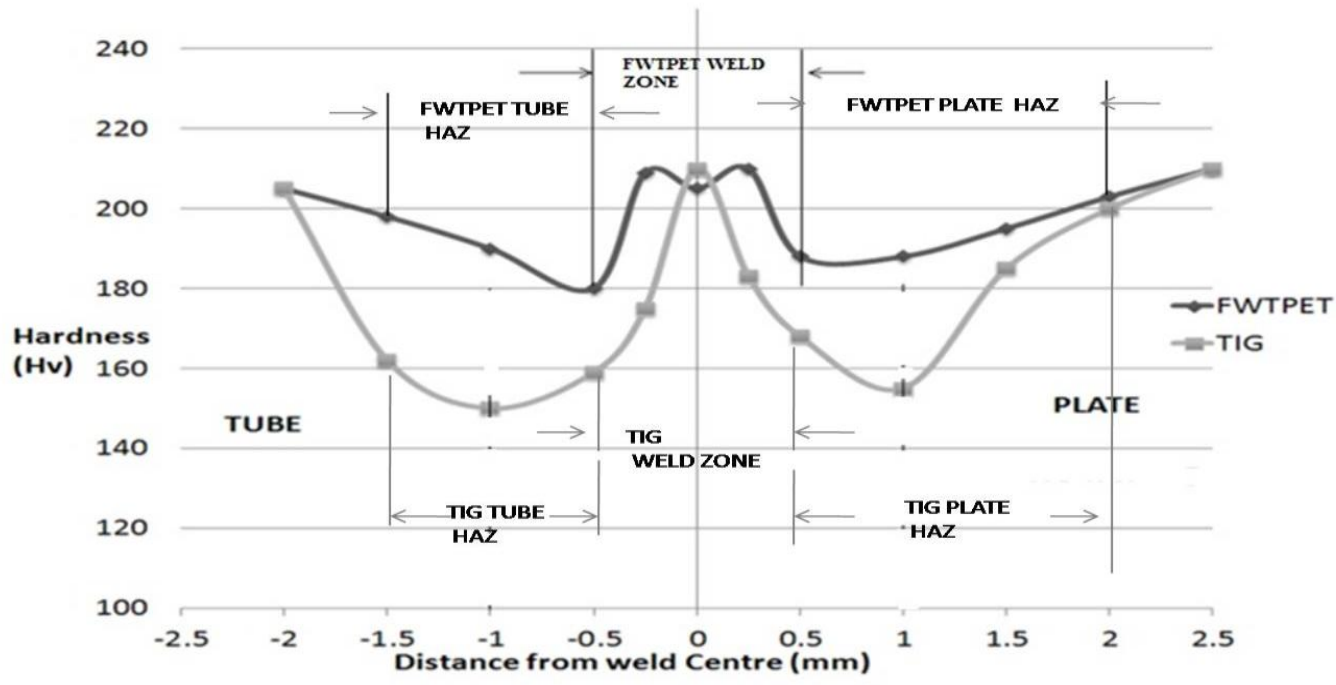

Fig. 8 Comparison of hardness profile of FWTPET joint \& TIG welded joint.

\subsection{Comparative Study:}

FWTPET welded joints shown less variation in hardness across the weldment when compared to TIG welded joints as shown in the Fig. 8. The width of HAZ is wide in case of TIG welded samples compared to FWTPET joints. Time require for welding one joint by FWTPET process is $75 \mathrm{Sec}$ where as time require for welding one joint by TIG welding is $220 \mathrm{Sec}$. So that, the productivity can be improved for joining tube to tube plate by using FWTPET process. From the macrostructure study it is clear that joint formation by FWTPET process is throughout plate thickness and tube wall but with TIG welding process it is observed only on the top. Weight of the component is increased by TIG 
welding process as the volume of filler wire consumed is $1105 \mathrm{~mm}^{3}$ but there is no filler material used during FWTPET process and there is no possible to increase the weight of the component.

\section{Conclusions:}

FWTPET is an innovative process which has been successfully used to join tube to tube plate of 304SS and has high potential industrial application.

1) Experimental results have been obtained by FWTPET process and better metallurgical bond has been achieved throughout the plate thickness. But it is difficult to achieve complete penetration by TIG process.

2) Width of HAZ is increased in TIG welded joints when compared to FWTPET joints.

3) FWTPET welded joints have been increased hardness across the weldment when compared to TIG welded joints.

4) TIG welded joints with less heat input has shown a better metallurgical aspects like low level of sensitization in $\mathrm{HAZ}$, and fine grain structure in the weld metal which will increase the ductility of the weld.

Hence it is clear from the present study that FWTPET joints are found to have good properties when compared with the TIG welded joints. However, further study is required to get better understanding about the process.

\section{References}

ASTM SEC VIII, Div. 1, Pressure vessels (1919).

John, C. L. and Damian J. K., Welding metallurgy and weldability of stainless steels (2005), p.141-185, John Wiley.

Krishanan, J. and Kakodkar, A., An experimental investigation into tube to tube plate welding using the impactor method, Journal of Material Processing Technology, Vol.22 (1990), pp.191-201.

Lima, A. S. A. and Nascimento, M., Sensitization evaluation of the austenitic stainless steel AISI 304L, 316L, 321 and 347, Journal of Materials Science, Vol. 40 (2005), pp.139- 144.

Lin, Y. C. and Lee K. H., Effect of preheating on the residual stress in type 304 stainless steel weldment, Journal of Material Processing Technology, Vol.63 (1997), pp.797-801.

Muthukumaran, S., A process for friction welding tube to tube sheet or plate by adopting an external tool. Indian patent Application No. 189/ KOL, patent No. 21744, (2008).

Muthukumaran, S., Friction welding of tube to tube plate using an external tool-a study, International Welding Symposium 2k10, Vol.1 (2010), pp 241-245.

Muthukumaran, S., Pradeep, C., Vijaya Kumar, C. and SenthilKumaran, S., Mechanical and metallurgical Properties of Aluminium 6061 alloy tube to tube plate welded joints welded by friction welding using an external tool process, International Welding Symposium 2k10, Vol.1 (2010), pp. 235-239.

Park, C., Yutaka, S. S. and Hiroyuki Kokawa., Rapid formation of the sigma phase in 304 stainless steel during friction stir welding, Journal of Scripta Materials, Vol. 49 (2003), pp.1175-1180.

Park C., Yutaka S. S. and Hiroyuki Kokawa., Corrosion resistance of friction stir welded 304 stainless steel, Journal of Scripta Materials, Vol.51 (2004), pp.101-110.

Sathiya, P., Aravindan, S. and NoorulHaq, A., Mechanical and metallurgical properties of friction welded AISI 304 austenitic stainless steel, International Journal of Advanced Manufacturing and Technology, Vol. 26 (2005), pp. $505-511$.

SenthilKumaran, S., Muthukumaran, S. and Vinodh, S., Optimization of friction welding of tube to tube plate using an external tool, Structural and Multidisciplinary Optimization, Vol.42 (2010), pp.449-457.

SenthilKumaran, S., Muthukumaran, S. and Vinodh, S., Optimization of friction welding of tube to tube plate using an external tool by hybrid approach, Journal of Alloys and Compounds, Vol. 509 (2011), pp. 2758-2769.

SenthilKumaran, S., Muthukumaran, S. and Vinodh, S., Experimental and numerical investigation of weld joints produced by friction welding of tube to tube plate using an external tool International Journal of Engineering, Science and Technology, Vol. 2, No. 5, (2010), pp. 109-117.

SindoKuo., Welding Metallurgy, (2004), p.141-300, A Wiley Interscience publication. 